\title{
ПРОБЛЕМА ПСИХОЛОГИЧЕСКОГО СИНДРОМА ЭМОЦИОНАЛЬНОГО ВЫГОРАНИЯ МЕДИЦИНСКИХ РАБОТНИКОВ
}

\author{
Бухаров Дмитрий Сергеевич \\ студент
}

Научный руководитель: Коваленко Светлана Васильевна

канд. психол. наук, доцент

ФГБОУ ВО «Нижневартовский государственный университет»

Аннотация: В статье изложены основы понятия эмоционального выгорания, факторы, способствуют развитию синдрома профессионального выгорания и особенности появления профессионального выгорания у медицинских работников. В заключении представлены результаты исследования эмоционального выгорания у медицинских работников.

Ключевые слова: выгорание, факторы, стресс, эмоции, работник,

Интерес к проблеме синдрома эмоционального выгорания, в первую очередь, обусловлен ростом общечеловеческих проблем, оказывающих негативное воздействие на физическое, психоэмоциональное состояние человека, а также на эффективность выполняемых им профессиональных функций и на отношения с окружающими его людьми.

Изначально, число профессий, подверженных эмоциональному выгоранию, было сравнительно невелико - это были сотрудники учреждений и организаций, занимавшихся благотворительностью и социальной помощью нуждающимся. Но, с течением времени и вследствие роста тенденции к индивидуализации отдельного человека и его личному достижению, в то время как такие, основополагающие, структуры, как семья и близкий круг социального взаимодействия, ушли на второй план, проблема эмоционального выгорания возникла как социальный феномен. Это сподвигли людей, вместо самостоятельного анализа проблемы и поиска решения, идти за ответами к профессионалам, что увеличило как востребованность консультации и помощи, так и нагрузку на специалистов. Результатом подобных изменений стало расширение спектра категорий подверженных профессиональному выгоранию. 
Впервые, на эту проблему, обратили своё внимание американские специалисты, в связи с организацией и массовым распространением социальных служб, сотрудники которых, обладая специальными психологическим образованием и специальными навыками, систематически вступали в контакт с посетителями, что приходили к ним со своими разными и, как правило, тяжёлыми проблемами. Однако, спустя время, несмотря на специальную подготовку и грамотный подбор специалистов, руководители центров помощи сталкивались с жалобами на своих сотрудников. В первую очередь, возникали жалобы посетителей на невнимательность сотрудников, их равнодушие, или даже грубость. Проведенные исследования привели к обнаружению своеобразного профессионального стресса - «стресса общения», который в сочетании с другими профессиональными стрессами, приводит к возникновению состояния крайней степени эмоционального истощения и деперсонализации [6].

Американский психиатр, Герберт Фрейденберг, с целью охарактеризовать психологическое состояние здоровых людей, находящихся в регулярном и интенсивном взаимодействии с людьми, вследствие чего, пребывающих эмоционально насыщенной атмосфере, при оказании профессиональной помощи, вывел понятие «эмоционального сгорания». Изначально, термин «burnout» характеризовался, как состояние изнеможения, истощения с ощущением собственной бесполезности. Однако, со временем, и в результате возросшей эмпирической базой исследования проблемы, термин приобрел свою окончательную форму, как «Эмоциональное выгорание» [9].

Эмоциональное выгорание - это процесс постепенной утраты эмоциональной активности и физической энергии, проявляющийся через симптомы эмоционального и умственного истощения, личной отстраненности и снижения удовлетворенности результатами выполняемой работы; специфический синдром, развивающийся с течением профессиональной деятельности, на всем временном промежутке, его профессиональной активности и выражающийся, также в отчуждении от людей, с которыми человек взаимодействует, а также в отсутствии профессиональных планов на будущее и крупные надежды. Под эмоциональным истощением понимается ощущение эмоциональной опустошённости и усталости, вызванное собственной профессиональной деятельностью. Деперсонализация характеризуется, как циничное отношение к труду и объектам и предметам труда. В социальной сфере деперсонализация предполагает бесчувственное, 
негуманное отношение к людям, приходящим за помощью в той, или иной сфере, выполняемой специалистом, деятельности. Социальное взаимодействие с людьми становится формальными, обезличенными; возникающие негативные установки могут поначалу иметь скрытый характер и проявляться во внутренне сдерживаемом раздражении, которое со временем прорывается наружу и приводит к конфликтам.

Стоит отметить, что эмоциональное выгорание неразрывно связано с тесно связано с выполнением человеком его профессиональных функций, следовательно, более целесообразно рассматривать эмоциональное выгорание, в контексте профессионального выгорания, как комплекса негативных переживаний, на фоне профессиональной деятельности, межличностного взаимодействия в коллективе и всей организации в целом.

В зарубежной литературе, одной из концепций, характеризующей профессиональное выгорание, является трёхфакторная модель выгорания предложенная К. Маслач, С. Джексоном и А. Пином. Согласно данной теории, синдром эмоционального выгорания представляет из себя трехфакторную структуру, включающую в себя такие: эмоциональное истощение; деперсонализацию и редукцию личностных достижений. Эмоциональное истощение рассматривается, как основополагающий фактор эмоционального выгорания и проявляется в сниженном эмоциональном фоне, равнодушии или эмоциональном перенасыщении. Сотрудники помогающих профессий, такие как: педагоги, медики, социальные работники, священнослужители, психологи, а также сотрудники культурно-досуговой, обслуживающей сферы и т. д., в соответствии с особенностями условий трудовой деятельности и её специфики, должны много времени взаимодействовать с другими людьми. Результатом систематического социального взаимодействия становится устойчивое эмоциональное напряжение, что, со временем, ведет к таким эмоциональным проявлениям как апатия, раздражение, развивается ощущение бессмысленности собственных действий, атрофией сочувствия и сопереживания другим [9].

Основу подходов к изучению проблем эмоционального и профессионального выгорания, в зарубежной психологии составляет, выдвинутая Гансом Селье, теория стресса. Он понимал эмоциональное выгорание, как физиологический синдром, что становится неспецифический ответ организма, на складывающиеся в ходе профессиональной деятельности, из неспецифически вызванные изменения [1]. 
На основе того, что реакции организма на стресс являются независимыми от их специфики, Г. Селье сформулировал понятие общего адаптационного синдрома, состоящего из трех фаз: 1. «Реакция тревоги», что характеризуется снижением уровня сопротивляемости организма факторам внешней среды - это является первой и естественной реакцией на стресс; 2. «Сопротивление», что основывается на мобилизации ресурсов организма, с целью повышения его сопротивляемости; 3. «Истощение» характеризуется резким спадом сопротивляемости, в результате исчерпания организмом запасов энергии. Как следствие, возможно образование новых, или обострение имеющихся хронических, соматических заболеваний [2].

Исследования Г. Селье подтверждают, что человеческому организму присущ и возможен для выявления так называемый «оптимальный» уровень стресса, не наносящий вред внутренним системам, а даже являющийся полезным, поскольку он способствует адаптации к изменяющимся условиям. Однако, в результате длительного воздействия, происходит перегрузка, которая приводит к психологическим и физиологическим срывам в организме. С позиции Г. Селье, возникающий во время социального взаимодействия психологический стресс, формируется, как столкновение интересов и стрессоров, результатом чего становится возникновение сбалансированного импульса - приказа к сопротивлению.

В отечественной психологии, развитие сферы исследования профессионального выгорания, получило своё начало, также, в связи с развитием теории стресса. Хоть и понятие профессионального выгорания стало употребляться значительно позже, проводимые исследования, уже тогда определили его четкое содержание и характеристики, данного явления.

Первые исследования, связанные с эмоциональным выгоранием, были проведены на учителях в начале XX века А. С. Шафрановой и ее коллегами. Итогом исследований стали выводы, что существуют индивидуальные особенности учителей, которые способны, определённым образом воздействовать на их психическую утомляемость и эффективность в профессиональной деятельности. Результаты этих исследований легли в основу работы в сфере профессиональной деформации преподавателей, а также выделили такие особенности профессиональной деятельности педагога, которые способствуют развитию процесса выгорания. Этими факторами стали: непрекращающееся внутреннее ощущение того, что каждая ситуация, связанная с трудом - новая; Эффективность профессиональной деятельности 
находится, в большей степени, зависимой не от предмета труда, а от индивидуальных особенностей трудящегося; Высокие требования к саморазвитию; Эмоциональность и напряженность социального взаимодействия. Постоянные и интенсивные социальные контакты; Персональная ответственность не только за результат профессиональной деятельности, но и за уровень воспитанности, образованности, нравственной культуры обучающихся; [7].

Анализ отечественной психологической литературы, связанной с проблемой профессионального выгорания, позволяет выделить два основных подхода к пониманию данной проблемы: 1. Экзистенциальный подход, характеризующий профессиональное выгорания как возникающий из-за деформации ценностно-смысловой сферы личности. Ограничение, данного явления, лишь понятием профессионального стресса, по мнению авторов, сужает взгляд на проблему и уменьшает спектр возможностей для его изучения, поскольку утрата смысла профессиональной деятельности является потерей части смысла всей жизни. Утрата смысла профессиональной деятельности способствует развитию, у профессионала, экзистенциального вакуума, характеризующегося субъективными переживаниями скуки, апатии и пустоты. 2. В соотношении с теорией стресса, проблема профессионального выгорания, рассматривается, как закономерный ответ организма на продолжительное воздействие стресса в профессиональной деятельности. В этом случае выгорание затрагивает все сферы жизни человека: физическую, умственную и эмоциональную [9].

В. В. Бойко рассматривает выгорание, как механизм психологической защиты личности, которая заключается «исключении» эмоций из жизни человека. Оно может быть как полным, так и частичным. Выгорание обладает собственной динамикой. Оно возникает и развивается постепенно и обладает собственной периодизацией, соответствующей этапам развития стресса. В. В. Бойко не видит в выгорании положительных особенностей, способствующих переосмыслению жизни. Выгорание - это лишь дисфункциональный феномен, ведущий к ухудшению профессиональной деятельности, сказывающийся на личностном развитии и потворствующий образованию соматических заболеваний [3].

Проблема синдрома профессионального выгорания становится всё более актуальной для специалистов, которые занимаются профессиональной деятельностью в сфере «человек-человек», к которым относится и профессия 
медицинского работника. Их деятельность, независимо от вида осуществляемой работы, относится к группе специальностей с высокой нравственной ответственностью за здоровье и жизнь отдельных людей, групп населения и общества в целом. Медицинские работники - это социальная группа с одной стороны, испытывающая на себе все тяготы и проблемы современного общества, с другой, они должны смягчить эти проблемы в процессе контакта населения с системой здравоохранения. Иными словами, медики находятся в кругу, как своих собственных проблем, так и проблем своих пациентов, неся при этом двойную социально-психологическую нагрузку.

Профессиональная деятельность медицинских работников предполагает высокую эмоциональную насыщенность при социальном взаимодействии с пациентами, в результате чего повышается процент факторов, способствующих возникновению профессионального стресса.

Эмоции людей, работающих в системе здравоохранения, являются амбивалентными. С одной стороны это удовлетворение собой в результате успешно проведённой операции или лечения, чувство значимости выполняемых профессиональных функций, но с другой, это чувство опустошения и угнетения, по причине неправильного диагноза или ошибки в лечении, зависть к преуспевающим коллегам, разочарование в профессии и т. п. Даже самые активные и увлечённые своим делом специалисты, сталкиваются с эмоциональным перенапряжением в результате интенсивной работы с большим количеством людей, страдающих от самых разных личностных, физических и социальных проблем.

Профессиональное выгорание медицинского работника выражается, в первую очередь, как чувство эмоционального истощения, деперсонализации и снижения уровня личных достижений. Медицинский работник начинает относиться к пациенту холодно, проявляя меньше заботы и внимания к его проблеме. Они могут начать лечить их безучастно и даже бесчеловечно. Они недовольны собой и тревожатся, считая, что не годятся для этой работы.

$\mathrm{C}$ ростом эмоционального истощения возникают проблемы с работоспособностью, ухудшаются отношения с коллегами, неурядицы в семье и плохое здоровье.

Способствует развитию профессионального выгорания у медицинских работников также объем прямых контактов с пациентами. Более продолжительная работа в непрерывном прямом контакте с пациентами 
сопряжена с более сильным изнурением. Это особенно актуально, когда речь идет о контактах, которые даются с большим трудом и приносят огорчение, как бывает с умирающими пациентами.

Профессиональная сфера, связанная с людьми, имеющими тяжелые хронические заболевания, является одной из самых сложных и эмоционально затратных. Негативные стороны работы в данной сфере выражаются через систематическую работу с сильными эмоциональными переживаниями, которая способствует формированию психологических защитных механизмов, направленных на снижение тяжести переживаний эмоций, связанных с выполнением профессиональной деятельности. Вследствие этого возможна утрата чувствительности к эмоционально- значимым переживаниям не только больных, но и ближайшего круга общения специалиста: близких друзей и родственников, попавших в трудную минуту.

Высокий уровень загруженности и недостаток материальных ресурсов, в некоторых случаях, не способствуют перспективам профессионального развития и роста, если организация не озабочена развитием своих специалистов. Посещение курсов повышения квалификации, различных научных конференций и семинаров становится затруднительным. С течением профессиональной жизни непрерывно накапливаются личные проблемы, неизбежно появляющиеся в эмоционально-травмирующих ситуациях в работе. В результате этого у медицинского работника исчезает страсть в выполнении своих профессиональных обязанностей, возникает чувство безысходности, что нет возможности ничего изменить, что всё это бессмысленно, а больной в любом случае обречён, или относится к специалисту, с точки зрения «потребителя» услуг. Появляется чувство и желание винить во всём самого себя, ч ленов семьи, коллег, начальство, систему здравоохранения вообще и государство, искать простейшие объяснения трудностям, появляющимися в процессе лечения больного.

Профессиональное выгорание выражается в форме растущего негативизма по отношению, как к больным, так и к сотрудникам, ощущении собственной профессиональной несостоятельности чувстве неудовлетворенности трудовой деятельностью, явлениях деперсонализации, а в результате в резком ухудшении качества жизни.

Всё это оказывает негативное воздействие на личность медицинского работника. Эмоциональное истощение заставляет чувствовать себя неудовлетворенно в профессии, возникает ощущение неуспешности. 
Появляется чувство неблагодарности работы, результатом чего становится образование отчуждённого отношения к пациенту. Медицинский работник, с течением времени, привыкает не привязываться к больным, равнодушно относиться к проблемам, что существенно понижает результативность работы. Результаты работы с определёнными категориями пациентов, бывают неощутимы и неконкретны, однако физические, эмоциональные и психологические затраты медицинского работника, даже в таком случае очень велики [1].

Иными словами, можно выделить основные аспекты, способствующие возникновению и развитию профессионального выгорания, такие как:

1. Внешние факторы, связанные с особенностями профессиональной деятельности: хронически напряженная психоэмоциональная деятельность, когда работнику приходится постоянно подкреплять эмоциями различные аспекты своей деятельности, «трудный» контингент, с которым приходится общаться; дестабилизирующая организация (обстановка) деятельности, тяжелые условия труда; повышенная ответственность за исполняемые функции и операции, повышенная требовательность руководства; неблагополучная психологическая атмосфера профессиональной деятельности, которая определяется двумя основными обстоятельствами: конфликтностью «по вертикали», т. е. между начальником и подчиненными, и конфликтностью «по горизонтали» - между коллегами.

\section{2. Внутренние факторы, связанные с индивидуальными} особенностями человека: склонность к эмоциональной ригидности. Выгорание чаще возникает у тех, кто менее реактивен и восприимчив, более эмоционально сдержан. У людей импульсивных, обладающих подвижными нервными процессами, формирование симптома выгорания происходит медленнее. Повышенная впечатлительность и чувствительность могут полностью блокировать этот механизм психологической защиты; интенсивная интериоризация (у людей с повышенной ответственностью больше шансов подвергнуться синдрому); слабая мотивация эмоциональной отдачи в профессиональной деятельности (низкий уровень эмпатии); нравственные дефекты и дезориентация личности.

3. Организационный фактор характеризуется особенностями профессиональной среды: многочасовым рабочим днём, монотонностью и однообразием выполняемых действий, несоответствием характера руководства содержанию работы, отсутствии возможностей и перспектив 
профессионального роста. Также своей влияние оказывают факторы: Содержание труда, что включает аспекты количественной и качественной трудовой деятельности, частоту их выполнения, степень глубину контакта и Социально-психологические факторы - взаимоотношения в организации, как по вертикали, так и по горизонтали. По мнению В. И. Ковальчука, риск возникновения профессионального выгорания значительно увеличивается при больших затратах работником личностных ресурсов, при монотонности и однообразии характера работы.

Стоит отметить, что именно личностному фактору, в возникновении и развитии факторов профессионального выгорания, отведена ведущая роль. Среди личностных особенностей, способствующих эмоциональному выгоранию, X. Дж. Фрейденберг выделяет эмпатию, гуманность, отвлекаемость, идеализированность, интровертированность, фанатичность. Труды отечественных исследователей проблемы профессионального выгорания позволяют выделить различные корреляции индивидуальноличностных характеристик с показателями профессионального выгорания. Так, на основе проведенных С. Иевлевой и Т. Шаталовой исследований выявлена взаимосвязь трех типов акцентуаций характера с развитием феномена эмоционального выгорания, таких как: 1. Педантичный тип. Он характеризуется сочетанием таких характеристик личности, как добросовестность, перфекционизм, дотошность и аккуратность, чрезмерное стремление к принятию идеального решения, во всех сферах жизни и любом деле. 2. Демонстративный тип. Представляет собой личность, стремящуюся быть на виду, даже при выполнении обыденной или рутинной деятельности. 3. Эмотивный тип. Проявляется через чрезмерную чувствительность, сентиментальность и впечатлительность переживаемыми событиями. При недостатке внутренней энергии для того, чтобы справиться с негативной ситуацией, такие люди способны переживать чужие эмоции фактически до саморазрушения, граничащего с патологией.

Изучая проблему профессионального выгорания, в рамках работы над магистерской диссертацией, нами было проведено исследование, направленное на анализ факторов эмоционального выгорания в сфере здравоохранения.

В исследовании приняли участие 28 медицинских работников (медсестёр и врачей), в возрастной группе от 30 до 65 лет. 
Результаты первичного исследования выявили:

Тест на профессиональный стресс (Т. Д. Азарных, И.М. Тыртышникова) выявил умеренный показатель, при котором стресс представляет безусловную проблему и очевидна необходимость коррекционных действий. Чем дольше будет продолжаться работа при таком уровне стресса, тем тяжелее что-либо сделать с ним. Это серьезный повод для тщательного анализа вашей профессиональной жизни. Такое нервное напряжение, по классификации синдрома эмоционального выгорания В. В. Бойко, можно охарактеризовать, когда человек уже ощущает раздражение, отчаяние и неудовлетворенность выполняемой им профессиональной социальной деятельностью.

Диагностика профессионального выгорания (К. Маслач, С.Джексон в адаптации Н. Е. Водопьяновой), выявила у испытуемых высокий уровень показателя эмоционального истощения, что может проявляться в чувстве эмоциональной опустошенности и усталости, вызванное профессиональной деятельностью. Множественные, эмоционально окрашенные взаимоотношения медицинских работников, наполняют каждый рабочий день специалиста, и, по результатам теста, выгорание как прогрессирующее явление мы определяем в высоком уровне деперсонализации у участников исследования. Определена редукция профессиональных достижений на высоком уровне, что выражается в негативном оценивании себя и своих профессиональных достижений.

В целом показатель общего выгорания соответствует средним значениям шкалы профессионального выгорания. Однако, несмотря на выраженное проявление всех трех компонентов профессионального выгорания, их сочетание не является крайним проявлением выраженности синдрома, но определенно является поводом для принятия не только профилактических, но и психо- коррекционных мероприятий.

\section{Опросник Самочувствия; Активности; Настроения (САН)} зафиксировал низкие показатели по всем трём шакалам, по котором можно сказать, что самочувствие, настроение и активность у медицинских работников снижены. Это говорит об общей эмоциональной усталости профессионалов и подтверждает необходимость работы.

На основе полученных эмпирических данных, была составлена программа мероприятий, направленная на снижение негативных проявлений и актуализацию личностных ресурсов стрессоустойчивости и формированию 
представлений об умении управлять эмоциональным и психологическим состоянием. А также, способствовала профилактике различных эмоциональных нарушений, через самосознание и поиск личностных ресурсов у участников программы.

После реализации программы было проведено повторное тестирование медицинских работников, по трем заявленным методикам, результаты которых продемонстрировали положительную динамику.

Результаты Теста на профессиональный стресс (Т. Д. Азарных, И.М. Тыртышников) продемонстрировали снижение среднего значения уровня стресса с умеренных, эквивалентных занятому и много работающему специалисту, до оптимального, не наносящего существенного вреда. Стресс больше не является проблемой для испытуемых.

Результаты теста Самочувствие, Активность, Настроение (САН), демонстрируют благоприятные изменения, что говорит о благоприятном состоянии испытуемых и о том, что у них преобладает хорошее настроение, характеризующееся продолжительным и устойчивым состоянием. Подтверждается рост активности и желания поддерживать социальные контакты, улучшилось общее самочувствие и настроение, что поспособствовало снижению уровня эмоционального напряжения.

Результаты диагностики профессионального выгорания (К. Маслач, С. Джексон в адаптации Н. Е. Водопьяновой): показали у испытуемых снижение общего выгорания. В том числе и по факторам: Эмоционального истощения до 14.0, что соответствует низкому уровню, что говорит об восстановлении эмоциональных, физических и энергетических ресурсов, снижении скорости утомляемости; Деперсонализации до 9.3, что эквивалентно среднему уровню. Это говорит об восстановлении желания социального взаимодействия, снижении раздражительности и терпимости в ситуациях общения, повышении оптимистичного отношения к другим; Редукции профессионализма до 15.7, что, в сравнении с первичными результатами, говорит о росте чувства профессиональной компетентности, удовлетворенности собой и повышения ценности выполняемых профессиональных действий. Повышении уровня рабочей мотивации и энтузиазма по отношению к работе. 


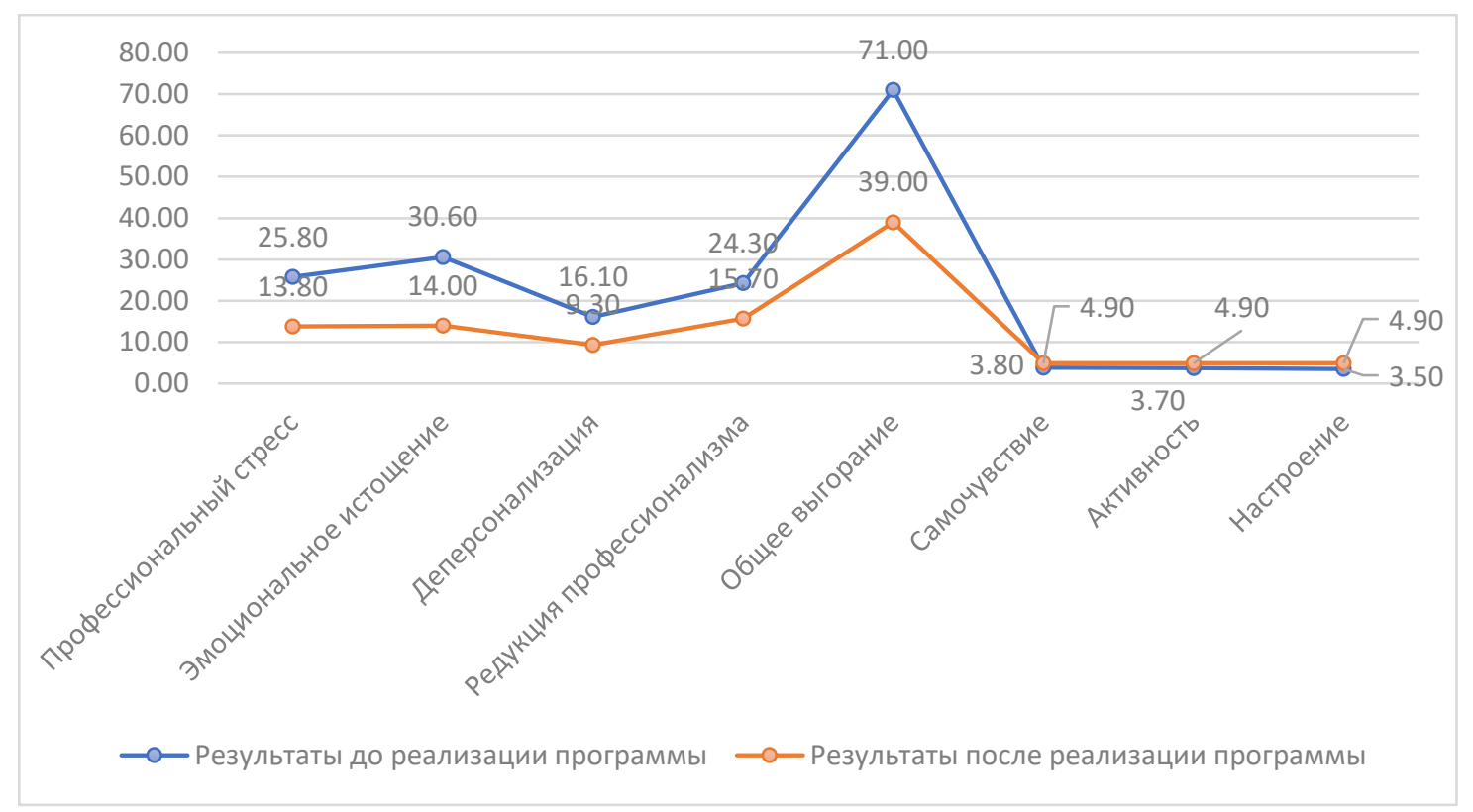

Рис.1 Сравнительный анализ результатов исследования

Таким образом, основываясь на результатах эмпирического исследования и анализа современной психологической литературы, мы видим, что профессия медика, является одной из наиболее подверженной негативному влиянию профессионального выгорания, поскольку она характеризуется высокой степенью эмоциональных переживаний, так как медицинские работники постоянно находятся как в кругу собственных, человеческих проблем, так и бед своих пациентов. Не стоит забывать и о том, что на врача возложена огромная ответственность за здоровье пациентов. Всё это создает двойную социально-психологическую нагрузку на личность медицинского работника.

Но результаты, показывает тестирование, после реализации программы, фиксируют значительные, положительные изменения: у участников программы произошло снижение уровня профессионального стресса, эмоционального истощения, деперсонализации и общего выгорания. Улучшились показатели самочувствия, активности и настроения, что позволяет констатировать эффективность реализации программы, a использование программы: на уровне организации и личности, позволяет решить вопросы предупреждения и преодоления синдрома профессионального выгорания у медицинских работников. А значит, и долгая, счастливая жизнь и качественное профессиональное нахождение, да и вообще всё в наших руках. 


\section{Список литературы}

1. Абрамова, Г.С. Психология в медицине / Г.С. Абрамова, Ю.А. Юдчиц. - М.: Наука, 1998. - С. 231-244.

2. Бабич, О.И. Личностные ресурсы преодоления синдрома профессионального выгорания/ О. И. Бабич // Иркутск: ИПКРО, 2009. - 172 с.

3. Бойко, В.В. Синдром «эмоционального выгорания» в профессиональном общении/В. В. Бойко. - СПб.: Питер, 1999. - 105 с.

4. Винокур, В.А. Профессиональный стресс у медицинских работников / В.А. Винокур // Вестник МАПО. - 2012. - № 2. - С. 25-30.

5. Водопьянова, Н.Е. Синдром выгорания: диагностика и профилактика/ Н. Е. Водопьянова, Е.С. Старченкова. - СПб.: Питер, 2005. - 336 с.

6. Косарев, В.В. Профессиональная заболеваемость медицинских работников Самарской области / В. В. Косарев, Г. Ф. Васюкова // Гигиена и санитария. - М.: Медицина, 2004. - № 3. - С.27-38.

7. Маслач, К. Профессиональное выгорание: как люди справляются/ К. Маслач // Школьный психолог. - 1998. - № 7 - С.16-18.

8. Огнерубов, Н.А. Синдром эмоционального выгорания у врачейтерапевтов/ Н.А. Огнерубов, М.А. Огнерубова// Вестник Тамбовского университета. Серия: Естественные и технические науки. - 2015. - №2. C. 307-318.

9. Орел, В.Е. Исследование феномена «психического выгорания» в отечественной и зарубежной психологии / В.Е. Орел // Проблемы общей и организационной психологии. - 2016. - № 4. -С. 70-97.

(C) Д.С. Бухаров, 2021 